\title{
The influence of sizing aging on the mechanical properties of epoxy-based carbon fiber composites
}

\author{
Luca Calamai \\ Italy, Independent
}

\begin{abstract}
The choice of type and quantity of sizing on the carbon fiber influences the wetting behavior and the strength of adhesion between fiber/sizing and resin. Here we investigate the influence of size aging on the adhesion between composite layers, through a measurement of Tensile Modulus.
\end{abstract}

Keywords: composites, epoxy, prepreg, carbon, sizing

\section{INTRODUCTION}

Fiber sizing is a thin homogenous coating applied on the surface of the fiber during production. This coating works by protecting the fiber when it's being manufactured. Aside from that, it also protects the fiber during post-processing operations including spreading, handling, compounding, weaving and molding. The fiber sizing formulations contain water, film formers in dispersed, dissolved or emulsified forms, coupling agents, plasticizers, anti-static agents, surfactants, rheology modifiers and antifoams. These sizing components have a shelf life, which affects the shelf life of the yarn.

\section{MATERIAL AND METHODS}

Raw materials: Carbon fiber spool yarn (nominal density $1.79 \mathrm{~g} / \mathrm{cm} 3$, nominal mass per unit length $445 \mathrm{~g} / \mathrm{Km}$ ) and Epoxy resin cured with DICY/Urea.

Twenty yarn samples were impregnated with a constant RC 30\% with epoxy matrix, and polymerized with a thermal cycle of 90 minutes at $130^{\circ} \mathrm{C}$; then were tested according to ASTM D4018.

The remainder of the yarn sample was stored 12 months in a climatic chamber at $21 \pm 3^{\circ} \mathrm{C}$ and $45 \pm 5 \% \mathrm{HR}$, and then other 20 specimens tested like the previous set.

\section{RESULTS AND DISCUSSION}

\begin{tabular}{|c|c|}
\hline First set of samples & $\begin{array}{c}\text { Second set of samples (stored } 12 \text { months at } 21+/-3{ }^{\circ} \mathrm{C} \\
\text { and } 45+/-5 \% \mathrm{HR} \text { ) }\end{array}$ \\
\hline $\begin{array}{c}\text { Tensile Modulus (GPa) 361.00 } \\
\text { Variation (\%) } 3.24\end{array}$ & $\begin{array}{c}\text { Tensile Modulus (GPa) } 320.33 \\
\text { Variation (\%) } 1.10\end{array}$ \\
\hline
\end{tabular}

\section{CONCLUSION}

The decrease in the value of Tensile Modulus in the aged sample suggest the need for prepreg producers to analyze in more detail the effect of yarn aging on mechanical properties of epoxy-based carbon fiber composites, as a crucial design factor. 